\title{
A Comprehensive Comparison between Finite Control Set Model Predictive Control and Classical Proportional-Integral Control for Grid-tied Power Electronics Devices
}

\author{
Abdulrahman J. Babqi*, Basem Alamri \\ Department of Electrical Engineering, College of Engineering, Taif University \\ KSA, P. O. Box 11099, Taif 21944, Saudi Arabia, b.alamri@tu.edu.sa \\ *Corresponding author: ajbabqi@tu.edu.sa
}

\begin{abstract}
Recently finite control set model predictive control (FCS-MPC) becomes a promising solution for controlling power electronics devices (PEDs). Although FCS-MPC produces variable switching frequency and steady-state error, it has many advantages such as the ease of implementation, controlling multiple parameters at the same time, and generating the switching signals internally. This paper aims to assess the performance of the FCS-MPC by constructing a comparative study of the FCS-MPC current control with the proportional-integral (PI) current control. For a fair comparison, the FCS-MPC average switching frequency was made to be equal or lower than the PI switching frequency. The study was performed on three different grid-connected PEDs, which are the three-phase two-level, single-phase full-bridge, and H5 inverters. Both control strategies were compared considering the switching frequency, common-mode voltage, leakage current, total harmonics distortion, and steady-state error. The results illustrate that the produced common-mode voltage and leakage current of the FCS-MPC are lower than PI in all cases. Even though FCS-MPC results in higher THD and steady-state error, they were maintained within acceptable limits. The three inverters and case studies were carried out to verify the performance of the controllers via the PSCAD/EMTDA software package.
\end{abstract}

Keywords: Model predictive control (MPC); Grid-connected inverters; Power electronics control; Common-mode voltage (CMV); Leakage current

\section{Introduction}

Renewable energy resources (RERs) become attractive alternatives over conventional power generation such as coal and natural gas since they are ecofriendly and fuel-free energy resources. However, some RERs especially wind and solar are not continuously available and their output power may vary considerably during the day [1]. The variation of renewable generation output causes some 
challenges to integrate them into the existing grid. For instance, the output direct current (DC) of a PV system must be converted to alternative current (AC) to be able to connect it to the grid. To this end, a controlled inverter is used to convert the DC to AC and regulate the grid's current. Such control ensures the stability and reliability of the PV power integration to the gird. In other words, power electronics devices (PEDs) facilitate merging these renewable energy resources with any electrical power system [2]. Nevertheless, integrating renewable energy resources via power electronics devices requires sophisticated control techniques [3]. Different control strategies have been proposed for controlling either gridconnected or islanded PEDs [4-9]. Among all, the most common and popular control strategy is the classical proportional-integral (PI) control method. The PI control uses the feedback mechanism to produce the error as the difference between the measured and reference values. The error then fed to the proportional and integral gains which produce the controlling signals. A tremendous number of literary works have proposed different PI control techniques for grid-tied PEDs [3]. A robust strategy for regulating the grid current entering a distribution network from a three-phase inverter system connected via an LCL filter was presented in [10]. The authors in [11] demonstrated different structures such as $d q$, stationary, and natural frame of PI control for the grid-side converter. A novel controller optimization algorithm using particle swarm optimization (PSO) in [12] for inverter output controllers.

Another widely used control strategy for PEDs is model predictive control (MPC) [13]. The goal of the MPC controller is to minimize the cost function considering the system constraints. It uses the system model to predict the step ahead of the controlled parameters. MPC applies the feedback mechanism to update the system in each time step for future disturbances. Only the first control action is implemented in each time step, and the rest is discarded. Therefore, MPC can predict the state's evolution over the prediction horizon. MPC can be classified into two groups for controlling PEDs, which are continuous control set MPC (CCS-MPC), and finite control set MPC (FCS-MPC) [14]. CCS-MPC utilizes the average model of the PED to perform the optimization process by minimizing the error between the predicted and reference values [15]. CCS-MPC generates continuous control signals and employs a modulator to generates the appropriate switching signals to the PED. Since this type of control uses an external modulator, it produces a fixed switching frequency, and that is considered the main advantage of CCS-MPC [16]. However, using CCS-MPC for controlling PEDs presents a very complex formulation of the optimization problems. This complex formulation can be reduced considerably by reformulating the optimization problem as a finite moving-horizon optimal control problem. In other words, FCS-MPC formulates the optimization problem based on the discreet nature of the PED, and that does not require an external switching signals generator. FCS-MPC evaluates each switching state of the PED and chooses the state that produces the lowest error. As a result, the computational time for solving the optimization problem is reduced significantly [17]. 
Many FCS-MPC algorithms have been proposed in the literature for controlling grid-connected PEDs. An early work of the authors in [18] presented the implementation of the FCS-MPC for controlling the output current of a threephase two-level inverter. This work verified that FSC-MPC avoids the use of external modulators, and the drive signals are generated internally. Moreover, it showed that the control method effectively manages the load currents and provides a satisfactory dynamical response. The authors claim that FCS-MPC is a very powerful tool that offers new possibilities for PEDs control and it can be used for different types of PEDs. A novel model-free predictive current control was proposed in [19] for a three-phase rectifier. The method eliminates the usage of the system model, multiplication operations, and tuning parameters. The technique slightly improved the current control than the original FCS-MPC algorithm. A multi-objective FSC-MPC was proposed for controlling a gridconnected and islanded three-phase inverter in [20]. This work showed that FCSMPC can perform multiple control actions at the same time such as current control and switching frequency reduction. The multiple control actions are included in the cost function, and a weighting factor is used to choose the priority of the controlled parameter. A reduced computational time FSC-MPC for a modular multilevel converter (MMC) was proposed in [21]. A grouping-sorting-optimized model predictive control with several modules was used for each arm of MMC current control. The method reduces the computational load of the FCS-MPC algorithm for MMC by considering a cascaded two-stage MPC. Reference [22] illustrated a proposed FCS-MPC for a five-level bidirectional converter. The authors confirmed that FCS-MPC improves the performance of the five-level converter in terms of efficiency and grid current total harmonics distortion. Using an extended state observer, [23] proposed an FCS-MPC of a three-phase inverter with a constant switching frequency. The method improves the current control and dynamic response of FCS-MPC for the three-phase inverter.

Numerous research works have compared the performance of the FCS-MPC with PI control for grid-tied PEDs [24- 29]. A comparison between FCS-MPC and PI for three-phase inverter current control was presented in [24, 25]. Both works compare the two controllers' performance in terms of step-change response, steady-state error (SSE), and total harmonics distortion (THD). The authors in [26, 27] proposed the FCS-MPC for controlling the output current of a quasi-Z-source inverter. The step-change response and THD of the FCS-MPC were compared with the PI control in [26] while the comparison was done based on the resultant THD and switching frequency $\left(f_{s}\right)$ in [27]. A model predictive control with a delay compensation method was proposed for a three-phase four-leg grid-tied inverter in [28]. The method was also compared with the PI control depending on step-change response and THD. An FCS-MPC was proposed for a new grid-tied three-IGBTs inverter in [29]. The authors compared the control strategy with PI and hysteresis control methods. They formed a comparison based on the stepchange response and THD. All the aforementioned research works have compared FCS-MPC with the classical PI strategy for different types of grid-connected 
PEDs based on only the produces total harmonics distortion, switching frequency, or step-change response. However, to the best of our knowledge, there is no existing work that compares the performance of the FCS-MPC with PI control based on the common-mode voltage (CMV) and leakage current adding to that total harmonics distortion, switching frequency, and steady-state error. Therefore, this paper presents a comprehensive comparison of the FCS-MPC versus classical PI control for different grid-connected PEDs. The study was done on three PEDs, which are three-phase two-level, single-phase full-bridge, and H5 inverters. The two control methods' performances were compared based on:

1) the switching frequency,

2) total harmonic distortion,

3) steady-state error,

4) common-mode voltage, and

5) leakage current.

The rest of the paper is organized as follows: Section 2 explains the system modelling. Section 3 describes the principle of the finite control set model predictive control and proportional-integral control strategies. Section 4 discusses the common-mode voltage and leakage current in power electronics devices. The case studies are presented in Section 5, and Section 6 concludes the paper.

\section{Systems Modeling and Description}

Several power electronic devices are used to transform the direct current to sinusoidal alternative current. Examples of these devices are the single-phase fullbridge, H5, and three-phase two-level inverters (Figure 1). Since each device has a distinct topology, a different control scheme is used to minimize the error between the measured and reference values. Control strategies that are typically applied to control power electronics devices are PI and FCS-MPC. PI controller acts only when the error between measured and reference values has occurred. On the other hand, the FCS-MPC controller can predict the error before it occurs, which makes the MPC more robust compared to other controllers. This work examines the performance of both PI and FCS-MPC controllers on three distinct power electronic devices, which are the single-phase full-bridge, the $\mathrm{H} 5$, and the threephase two-level inverters (Figure 1). Each device has a different configuration in terms of the number of switches and legs. The three-phase two-level inverter in Figure 1(a) consists of three legs with two switches in each leg while the fullbridge in Figure 1(b) is a single-phase inverter consists of two legs with two switches in each leg. 

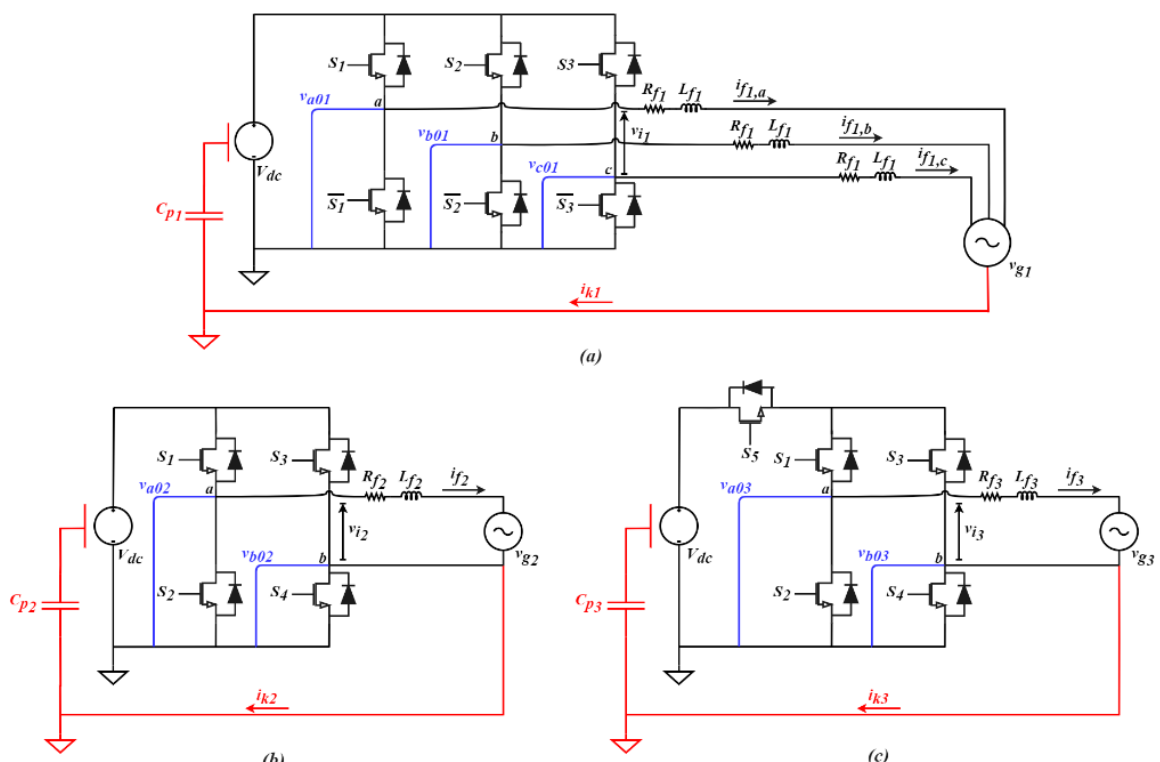

Figure 1

Power electronics devices used in this study: (a) three-phase two-level inverter, (b) single-phase fullbridge inverter, and (c) $\mathrm{H} 5$ inverter

The H5 inverter in Figure 1(c) is a modified version of the full-bridge inverter proposed by SMA Solar Technology [30]. In this modified version, one more switch $\left(S_{5}\right)$ is added to disconnect the DC source (e.g., PV system) from the utility grid during the zero operation modes, which results in reducing the leakage current, $i_{k}$ [31]. For system modeling, each inverter is connected to a DC source to represent the generator. Also, each inverter is connected to the grid through an inductor filter $L_{f}$, as shown in Figure 1.

The system modeling of each inverter (Figure 1) in case of grid-connected mode can be derived as

$v_{i}=v_{g}+v_{f}+R_{f} i_{f}$

where $v_{i}$ is the inverter output voltage, $v_{f}$ is the inductor voltage, and $v_{g}$ is the grid voltage. $i_{f}$ is the current flows between the inverter and utility grid. Using the filter inductor current dynamical equation,

$v_{f}=L_{f} \frac{d i_{f}}{d t}$

the continuous-time state-space model of the systems is

$\frac{d i_{f}}{d t}=\frac{1}{L_{f}}\left(v_{i}-v_{g}-R_{f} i_{f}\right)$ 


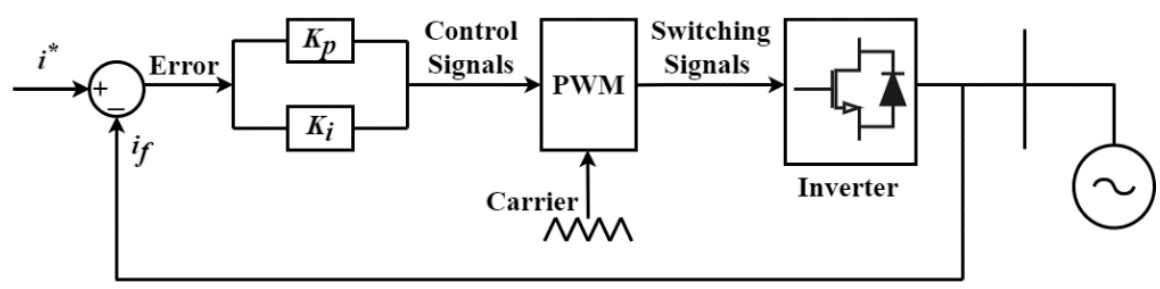

Figure 2

Proportional-integral control block diagram

Whether the inverter is a single- or three-phase, the continuous-time state-space equation can be used for modeling all power electronics devices in Figure 1.

\section{Controllers Modeling}

\subsection{Proportional-Integral Control}

The classical pulse width modulation (PWM) PI control method is a well-known technique for controlling the output current or voltage of the power electronics devices [32-34]. Figure 2 shows the basic principle of the PWM PI control for controlling the inverter output current. First, the measured current is used as a feedback in closed-loop control. Then, an error between the measured and reference values is fed to the PI controller, which produces the controlling signals. Finally, a PWM generator is used to produce the appropriate switching signals to the inverter. References [32] and [33] explain the implementation of the PI controller for both the single-phase full-bridge and $\mathrm{H} 5$ inverters, respectively. The PI controller using the PWM technique for the three-phase two-level inverter is presented in [34]. In this work, the control techniques in [32-34] are used to implement the PI control for all three inverters (Figure 1).

\subsection{Finite Control Set Model Predictive Control}

FCS-MPC is a finite moving-horizon optimal control method that uses the system model and local measurements for future values prediction of the controlled parameters. Figure 3 illustrates the FCS-MPC working principle [35]. First, the discrete-time model of the system is obtained. Then, the inverter output measurements are used with the system model to predict the controlled future values. Afterward, the error between the reference and future values is minimized using a cost function. Finally, switching signals are generated by the controller and sent to the inverter. FCS-MPC generates the switching signals internally 
based on space vector modulation (SVM) technique. Tables 1, 2, and 3 explain the SVM for the three-phase two-level, single-phase full-bridge, and H5 inverters, respectively.

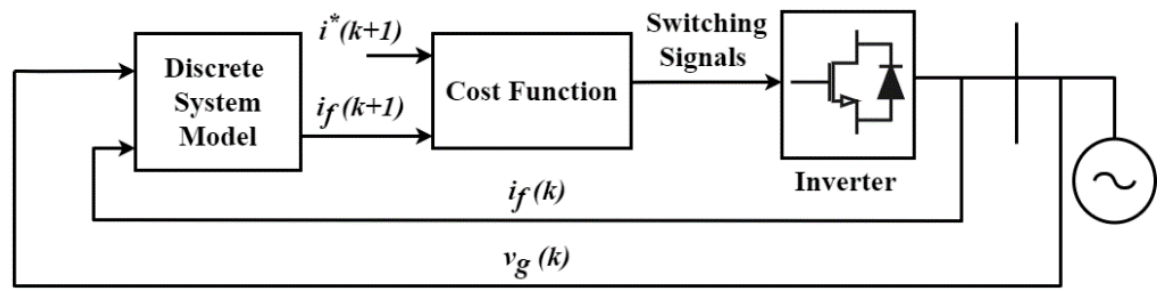

Figure 3

Finite control set model predictive control block diagram

Table 1 shows the upper switches $S_{1}, S_{2}$, and $S_{3}$ which control the three-phase two-level inverters while the lower once are switched conversely.

\subsubsection{FCS-MPC Current Control for Three-phase Two-level Inverter}

FCS-MPC for the three-phase two-level inverter is implemented in $a b c$ or $\alpha \beta$ reference frames. Since the latter reduces the mathematical operations performed by the controller [36], FCS-MPC is implemented in the $\alpha \beta$ reference frame for the three-phase two-level inverter in this work. The transformation from $a b c$ to $\alpha \beta$ is obtained using Clarke's transformation as

$\left[\begin{array}{l}x_{\alpha} \\ x_{\beta}\end{array}\right]=\frac{2}{3}\left[\begin{array}{ccc}1 & \frac{-1}{2} & \frac{-1}{2} \\ 0 & \frac{\sqrt{3}}{2} & \frac{-\sqrt{3}}{2}\end{array}\right]\left[\begin{array}{l}x_{a} \\ x_{b} \\ x_{c}\end{array}\right]$

using (3) in (4), yields

$\frac{d i_{f_{1, \alpha}}}{d t}=\frac{1}{L_{f_{1}}}\left(v_{i_{1, \alpha}}-v_{g_{1, \alpha}}-R_{f_{1}} i_{f_{1, \alpha}}\right)$

$\frac{d i_{f_{1, \beta}}}{d t}=\frac{1}{L_{f_{1}}}\left(v_{i_{1, \beta}}-v_{g_{1, \beta}}-R_{f_{1}} i_{f_{1, \beta}}\right)$

where the notation 1 refers to the three-phase two-level inverter parameters (Figure 1). The discrete-time model of (5a) and (5b) can be obtained using the Euler forward method to approximate the derivative [37].

$\frac{d x}{d t} \approx \frac{x(k)-x(k-1)}{T_{S}}$

Where $x(k)$ is the present value, $x(k-1)$ is the previous value, and $T_{s}$ is the sampling time. Applying (6) to (5a) and (5b), the discrete-time model of the system is 


$$
\begin{aligned}
& i_{f_{1, \alpha}}(k+1)=i_{f_{1, \alpha}}(k)+\frac{T_{S}}{L_{f_{1}}}\left(v_{i_{1, \alpha}}(k)-v_{g_{1, \alpha}}(k)-R_{f_{1}} i_{f_{1, \alpha}}(k)\right) \\
& i_{f_{1, \beta}}(k+1)=i_{f_{1, \beta}}(k)+\frac{T_{s}}{L_{f_{1}}}\left(v_{i_{1, \beta}}(k)-v_{g_{1, \beta}}(k)-R_{f_{1}} i_{f_{1, \beta}}(k)\right)
\end{aligned}
$$

Table 1

Space Vector Modulation of Three-phase Two-level Inverter

\begin{tabular}{|c|c|c|c|c|}
\hline State & $S_{1}$ & $S_{2}$ & $S_{3}$ & $v_{i 1}$ \\
\hline $\mathbf{0}$ & 0 & 0 & 0 & 0 \\
\hline $\mathbf{1}$ & 0 & 0 & 1 & $\frac{2}{3} V_{d c} \angle 0$ \\
\hline $\mathbf{2}$ & 0 & 1 & 1 & $\frac{2}{3} V_{d c} \angle 60$ \\
\hline $\mathbf{3}$ & 0 & 1 & 0 & $\frac{2}{3} V_{d c} \angle 120$ \\
\hline $\mathbf{4}$ & 1 & 1 & 0 & $\frac{2}{3} V_{d c} \angle 180$ \\
\hline $\mathbf{5}$ & 1 & 0 & 0 & $\frac{2}{3} V_{d c} \angle 240$ \\
\hline $\mathbf{6}$ & 1 & 0 & 1 & $\frac{2}{3} V_{d c} \angle 300$ \\
\hline $\mathbf{7}$ & 1 & 1 & 1 & 0 \\
\hline
\end{tabular}

Table 2

Space Vector Modulation of Single-phase Full-bridge Inverter

\begin{tabular}{|c|c|c|c|c|c|}
\hline State & $S_{1}$ & $S_{2}$ & $S_{3}$ & $S_{4}$ & $v_{i 2}$ \\
\hline $\mathbf{0}$ & 1 & 0 & 0 & 1 & $V_{d c}$ \\
\hline $\mathbf{1}$ & 1 & 0 & 1 & 0 & 0 \\
\hline $\mathbf{2}$ & 0 & 1 & 1 & 0 & $-V_{d c}$ \\
\hline $\mathbf{3}$ & 0 & 1 & 0 & 1 & 0 \\
\hline
\end{tabular}

Table 3

Space Vector Modulation of H5 Inverter

\begin{tabular}{|c|c|c|c|c|c|c|}
\hline State & $S_{1}$ & $S_{2}$ & $S_{3}$ & $S_{4}$ & $S_{5}$ & $v_{i 3}$ \\
\hline $\mathbf{0}$ & 1 & 0 & 0 & 1 & 1 & $V_{d c}$ \\
\hline $\mathbf{1}$ & 1 & 0 & 0 & 0 & 0 & 0 \\
\hline $\mathbf{2}$ & 0 & 1 & 1 & 0 & 1 & $-V_{d c}$ \\
\hline $\mathbf{3}$ & 0 & 0 & 1 & 0 & 0 & 0 \\
\hline
\end{tabular}

The output current future value of the three-phase two-level inverter is predicted by (7a) and (7b). The present values measurements $v_{g_{1}}(k)$ and $i_{f_{1}}(k)$ along with the inverter voltage $v_{i_{1}}(k)$ are used to predict the output current future value. Since $v_{i_{1}}(k)$ can be one of the eight values (Table 1), that will result in eight 
future values for the predicted current. Therefore, the cost function (8) is used to investigate each voltage vector and select the one that produces the lowest error between the reference current $\left(i^{*}(k+1)\right)$ and the predicted values. Once the optimal vector is selected, the related switching signals are sent to the inverter. This control procedure occurs in every sampling period $T_{s}$.

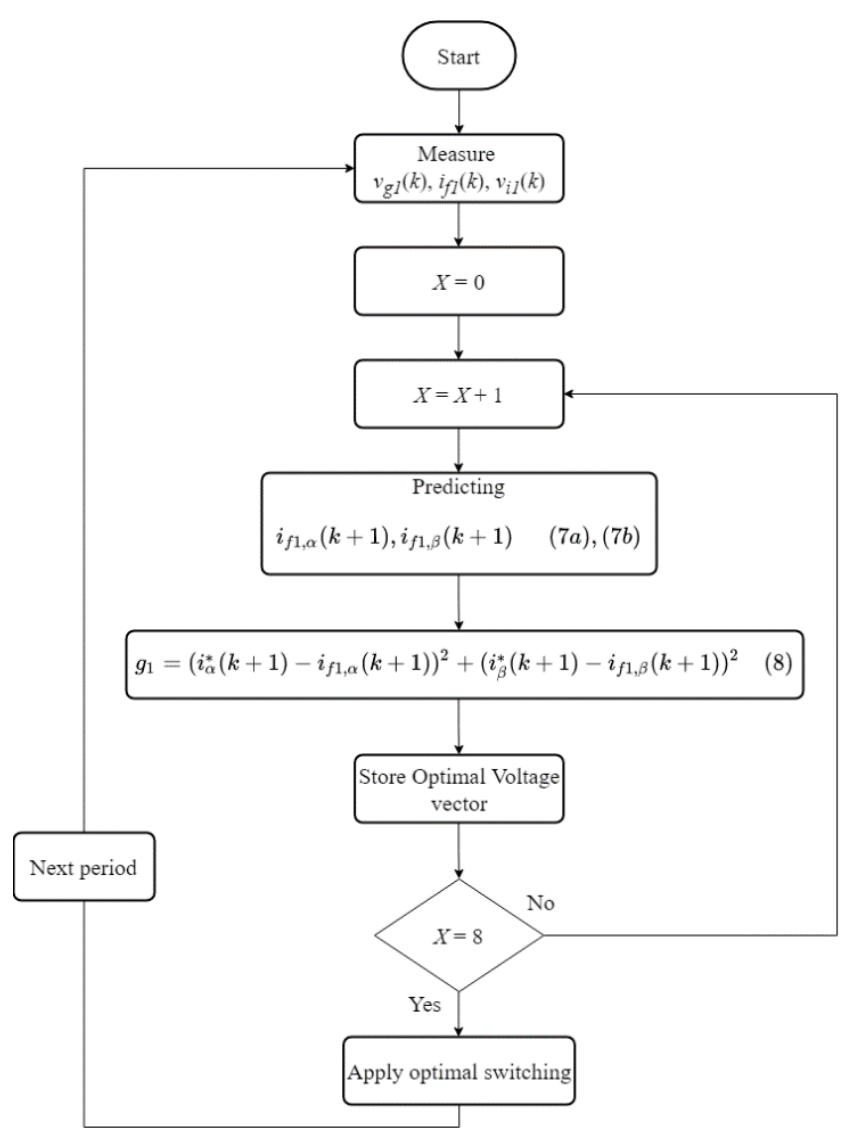

Figure 4

Flowchart of Finite control set model predictive for Three-phase Two-level Inverter

Figure 4 illistrates the algorithm process of the FCS-MPC for Three-phase Twolevel Inverter.

$g_{1}=\left(i_{\alpha}^{*}(k+1)-i_{f_{1, \alpha}}(k+1)\right)^{2}+\left(i_{\beta}^{*}(k+1)-i_{f_{1, \beta}}(k+1)\right)^{2}$ 


\subsubsection{FCS-MPC Current Control for Single-Phase Full-Bridge and H5 Inverters}

Since full-bridge and H5 are single-phase inverters, there is no need for using any transformation process. Therefore, the discrete-time model for both inverters can be directly derived from (3) using (6) which result in

$i_{f_{2,3}}(k+1)=i_{f_{2,3}}(k)+\frac{T_{s}}{L_{f_{2,3}}}\left(v_{i_{2,3}}(k)-v_{g_{2,3}}(k)-R_{f_{2,3}} i_{f_{2,3}}(k)\right)$

where thenotations 2 and 3 refer to full-bridge and H5 inverters parameters, respectively (Figure 1). Since the full-bridge and H5 inverters have four states as it is illustrated in Tables 2 and 3, there will be four future values of the predicted current for both inverters. Smellier to (8), the cost function (10) is used to determine the optimal voltage vector.

$g_{2,3}=\left(i^{*}(k+1)-i_{f_{2,3}}(k+1)\right)^{2}$

\subsubsection{Second Step Prediction}

As mentioned previously, FCS-MPC is optimal control and requires solving a large number of mathematical equations. As a result, a time-delay might occur while the controller solves the optimization problems and performs the control actions within one sampling period [38]. Therefore, a second step prediction $x(k+2)$ is preferred over the first step $x(k+1)$. To predict the second step of the controlled variables, the first step prediction should be obtained first (11a). Then, the first step prediction is used to predict the second step (11b).

$i_{f}(k+1)=i_{f}(k)+\frac{T_{s}}{L_{f}}\left(v_{i}(k)-v_{g}(k)-R_{f} i_{f}(k)\right)$
$i_{f}(k+2)=i_{f}(k+1)+\frac{T_{s}}{L_{f}}\left(v_{i}(k)-v_{g}(k+1)-R_{f} i_{f}(k+1)\right)$

As the grid frequency is much smaller than the sampling frequency, it can be considered [39].

$v_{g}(k+1)=v_{g}(k)$

Therefore, (11b) can be written as

$i_{f}(k+2)=i_{f}(k+1)+\frac{T_{s}}{L_{f}}\left(v_{i}(k)-v_{g}(k)-R_{f} i_{f}(k+1)\right)$

and the cost functions (8) and (10) are modified as

$g_{1}=\left(i_{\alpha}^{*}(k+2)-i_{f_{1, \alpha}}(k+2)\right)^{2}+\left(i_{\beta}^{*}(k+2)-i_{f_{1, \beta}}(k+2)\right)^{2}$
$g_{2,3}=\left(i^{*}(k+2)-i_{f_{2,3}}(k+2)\right)^{2}$ 


\section{Common-Mode Voltage}

CMV is the potential between the source and load neutral point. In the case of using a grounded DC source, the common-mode voltage can cause a large leakage current $i_{k}$ (Figure 1 ) flows between the DC source and the grid through a parasitic capacitor, which causes safety hazards and reduces the overall efficiency [31]. The common-mode voltage for the three-phase two-level inverter is calculated as in (16) while (17) is used to determine the common-mode voltage for both fullbridge and $\mathrm{H} 5$ inverters [40] (Figure 1).

$v_{c m_{1}}=\frac{v_{a 0_{1}}+v_{b 0_{1}}+v_{c 0_{1}}}{3}$
$v_{c m_{2,3}}=\frac{v_{a 0_{2,3}}+v_{b 0_{2,3}}}{2}$

\section{Simulation Results and Case Studies}

Three case studies were conducted to compare FCS-MPC and PI control performances on three different PEDs which are the single-phase full-bridge, H5, and three-phase two-level inverters (Figure 1). The three systems of were simulated using PSCAD/EMTDC platform. The comparison of the controllers' performance is based on five indicators:

- $\quad$ switching frequency $\left(f_{s}\right)$,

- total harmonic distortion (THD),

- $\quad$ steady-state error (SSE),

- $\quad$ common-mode voltage (CMV), and

- leakage current $\left(i_{k}\right)$.

Based on these five indicators, case study 1 investigates the performance of the two controllers on the single-phase full-bridge inverter while case studies 2 and 3 investigate the controllers' performance on $\mathrm{H} 5$ and three-phase two-level inverters, respectively. As it is known that the FCS-MPC average switching frequency $\left(f_{s, M P C}\right)$ is not constant. Therefore, $f_{S, M P C}$ was set to be lower or equal to the PI controller switching frequency $\left(f_{s, P I}\right)$ to present fair comparisons. In other words, the average switching frequency of FCS-MPC does not exceed the PI controller switching frequency at any operating point. The parameters values of the three systems are provided in Table 4. The PI switching frequency was set to $3.6 \mathrm{kHz}$. The sampling time values of FCS-MPC for three-phase, single-phase full-bridge, and $\mathrm{H} 5$ inverters were set to 50,40 , and $45 \mu \mathrm{sec}$, respectively. 
Since the grid voltage was set to $380 \mathrm{~V}$, the acceptable THD at the grid side should not exceed $8 \%$ [41].

\subsection{Case Study 1: Single-Phase Full-Bridge Current Control}

In this case study, PWM PI and FCS-MPC control strategies were implemented to control the single-phase full-bridge inverter's output current. Figure 5 shows the two controllers' resultant switching frequency $\left(f_{s}\right)$, common-mode voltage (CMV), and leakage current $\left(i_{k}\right)$ to the reference current $\left(i^{*}\right)$ where the horizontal axis represents $i^{*}$, and the vertical axis represents the responses of $f_{s}, \mathrm{CMV}$, and $i_{k}$. It should be noted that the reference current value increased from 0 to 1 p.u.

Table 4

Systems Parameters

\begin{tabular}{|c|c|c|}
\hline Parameter & Symbol & Value \\
\hline DC-link Voltage & $V_{d c}$ & $1 \mathrm{kV}$ \\
\hline Filter Inductance & $L_{f_{1}}$ & $3 \mathrm{mH}$ \\
\hline ESR of $L_{f_{1}}$ & $R_{f_{1}}$ & $0.04 \Omega$ \\
\hline Filter Inductance & $L_{f_{2,3}}$ & $5 \mathrm{mH}$ \\
\hline ESR of $L_{f_{2,3}}$ & $R_{f_{2,3}}$ & $0.05 \Omega$ \\
\hline Parasitic Capacitor & $C_{p_{1}}$ & $100 \mu \mathrm{F}$ \\
\hline Parasitic Capacitor & $C_{p_{2,3}}$ & $500 \mu \mathrm{F}$ \\
\hline Utility Grid Voltage & $V_{g 1}$ & $380 V_{L L, R M S}$ \\
\hline Utility Grid Voltage & $V_{g 2,3}$ & $380 V_{L G, R M S}$ \\
\hline Grid Frequency & $f_{g r i d}$ & $60 \mathrm{~Hz}$ \\
\hline
\end{tabular}

The average switching frequency of the FCS-MPC was set to be similar or lower than the classic PI controller switching frequency. Figure 5 illustrates that the $f_{S, M P C}$ does not exceed $f_{S, P I}$ at all operating points, resulting in a fair comparison in the other four performance indicators, which are CMV, $i_{k}$, THD, and SSE. Since the CMV may increase the $i_{k}$ flowing in the system, reducing CMV mitigates the $i_{k}$ effect. In Figure 5, the FCS-MPC shows superiority over PI control in terms of CMV and $i_{k}$. As shown in Figure 5, the resultant commonmode voltage of the FCS-MPC is maintained at a lower point around 0.4 p.u. compared to the PI controller at 0.5 p.u. It is clear that FCS-MPC reduces the leakage current by more than $100 \%$ compared to the linear controller at law reference value reaching around 50\% of leakage current reduction at 1 p.u. This performance improvement using FCS-MPC occurred since the controller 
eliminates the PI regulators and external modulators, and instead, it implements the SVM technique by considering a finite number of controlling vectors. Regarding THD, both FCS-MPC and PI show an almost similar response at high reference values while there is a very slight increase in the FCS-MPC's THD at lower operating points. This is closely related to the decrease of $f_{s, M P C}$ at low reference values. However, PI control shows a better SSE performance by almost $0.1 \%$ reduction at all operating points (Figure 6).

\subsection{Case Study 2: H5 Current Control}

In this case study, the system was reconfigured with $\mathrm{H} 5$ inverter to assess the FCS-MPC performance compared to the linear PI controller. The reference current had increased from 0 to 1 p.u. to examine the system response by assessing $f_{S}$, CMV, $i_{k}$, SSE, and THD.

It is clear that H5 inverter reduces the leakage current compared to the singlephase full-bridge (Figures 5 and 7) since $\mathrm{H} 5$ prevent the freewheeling current in the zero modes operation.
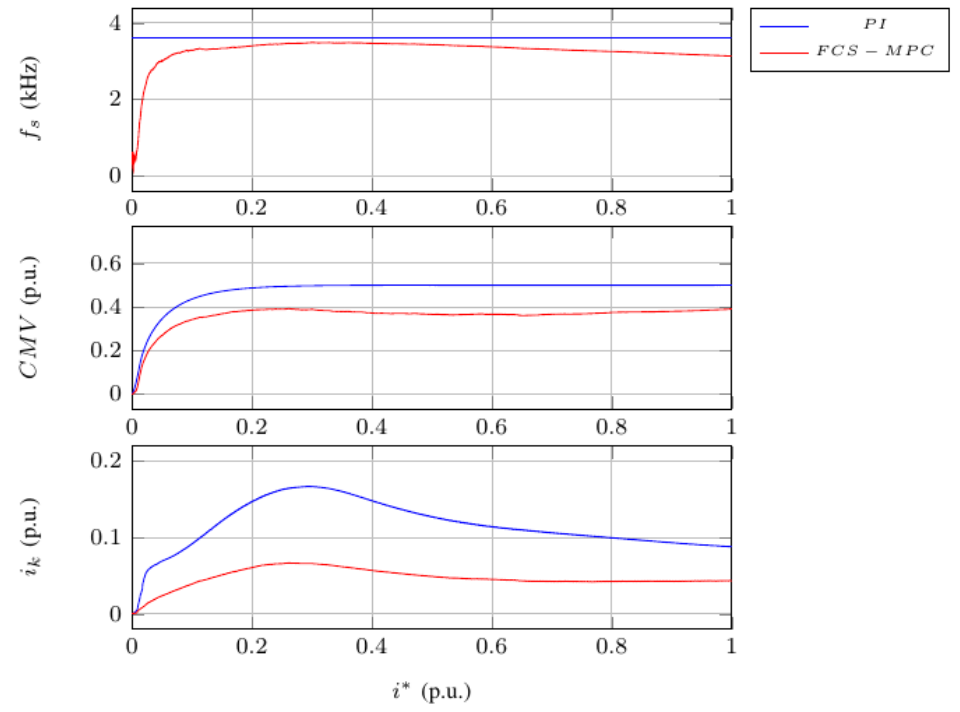

Figure 5

Single-phase full-bridge current control results: switching frequency $\left(f_{S}\right)$, common-mode voltage (CMV), and leakage current $\left(i_{k}\right)$ 

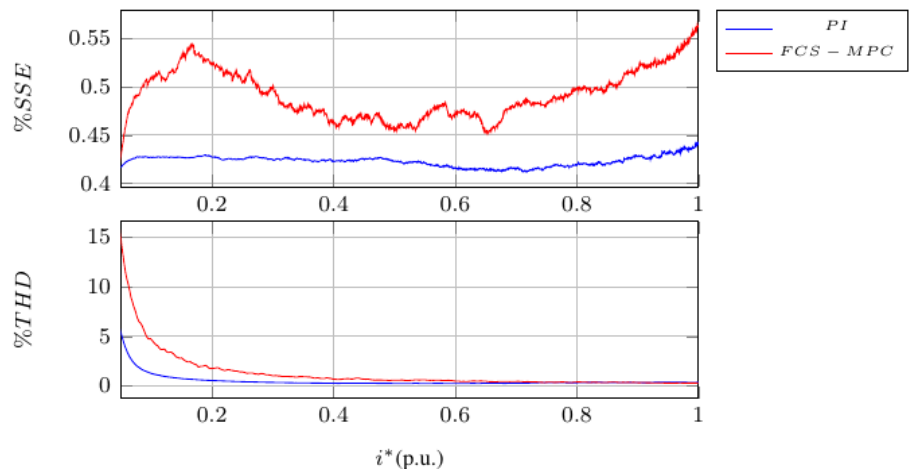

Figure 6

Single-phase full-bridge current control results: steady-state error (SSE), and total harmonics distortion

(THD)

Figure 7. Shows that $f_{S, M P C}$ is lower than $f_{S, P I}$ during the whole simulation period. Figure 7 shows that the system performance is enhanced with FCS-MPC, there is a noticeable decrease in both common-mode voltage, and leakage current of the FCS-MPC compared to the classic controller. At lower reference values, FCSMPC is capable of reducing the CMV by around 0.1 p.u. while it reduces the leakage current by 0.6 p.u. At higher operating points, both controllers result in almost similar CMV and leakage current.
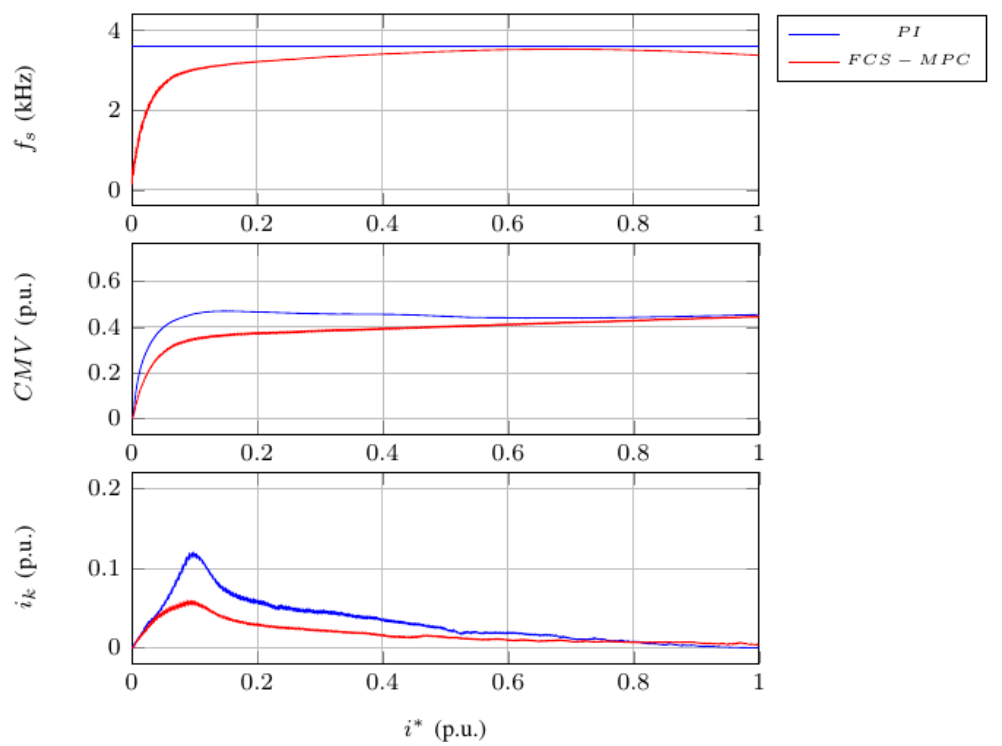

Figure 7

H5 current control results: switching frequency $\left(f_{S}\right)$, common-mode voltage (CMV), and leakage current $\left(i_{k}\right)$ 


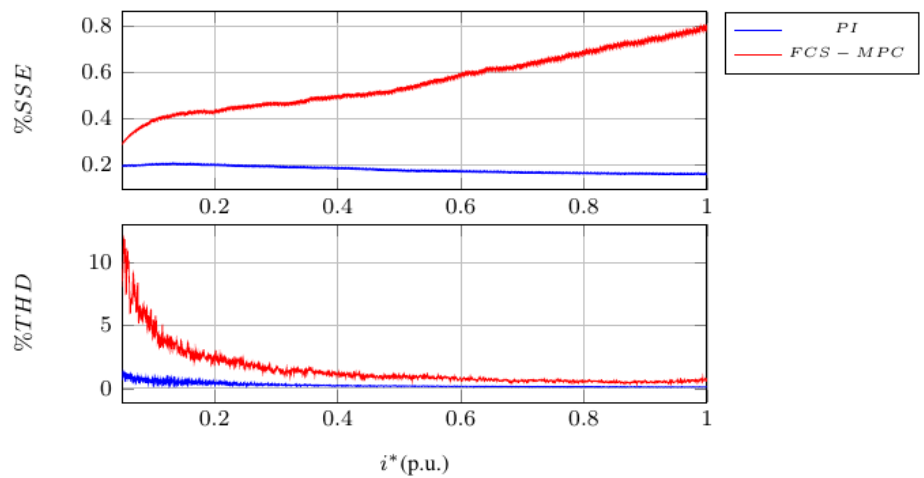

Figure 8

H5 current control results: steady-state error (SSE), and total harmonics distortion (THD)

On the other hand, PI provides a slight less THD by $0.4 \%$ compared to $2 \%$ of FCS-MPC at small reference values while both controllers result in almost similar THD at large reference values (Figure 8). In addition, PI has a fixed SSE at $0.2 \%$ compared to the FCS-MPC's SSE, which is increase from $0.4 \%$ at low operating points reaching $0.8 \%$ at 1 p.u. reference value.

\subsection{Case Study 3: Three-Phase Two-Level Inverter Current Control}

A three-phase full-bridge inverter was implemented in the following scenario to study the performance of the FCS-MPC compared to the classic PI controller by increasing the reference current significantly from 0 to 1 p.u. It is clear from Figure 9 that the system performance is enhanced by FCS-MPC, where the leakage current is significantly reduced by $50 \%$ of the PI leakage current. Another improvement is presented when the common-mode voltage is declined by 0.2 p.u. compared to PI at low operating points as shown in Figure 9. It can be observed from the Figures 9 and 9 the system response has improved with FCS-MPC compared to PI controller; However, there is an acceptable increase in the THD and SSE in both cases FCS-MPC Figure 10. 

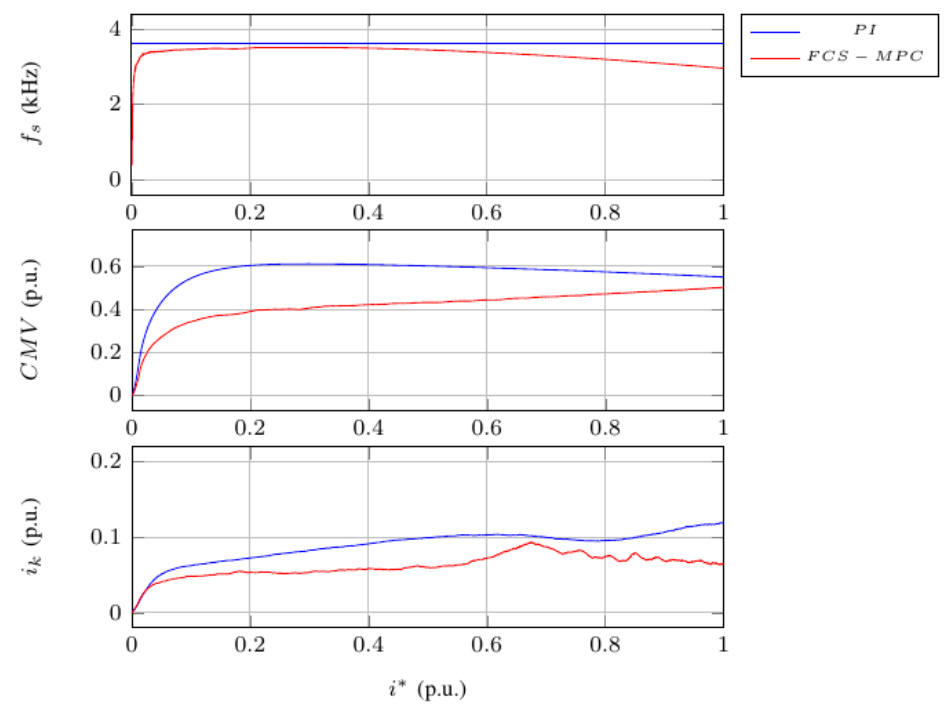

Figure 9

Three-phase two-level Inverter current control results: switching frequency $\left(f_{S}\right)$, common-mode voltage (CMV), and leakage current $\left(i_{k}\right)$
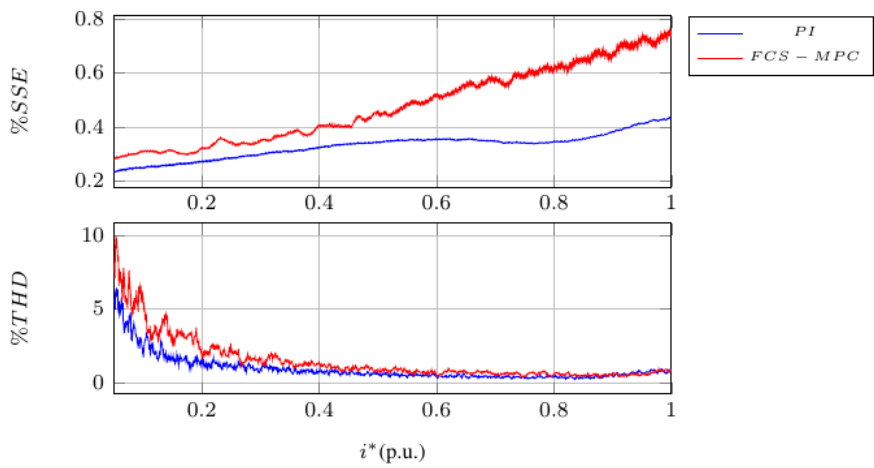

Figure 10

Three-phase two-level Inverter current control results: steady-state error (SSE), and total harmonics distortion (THD)

\section{Conclusions}

Among all control techniques, FSC-MPC getting more attention lately for controlling power electronics devices. In this paper, finite control set model predictive control has been compared with the proportional-integral pulls width modulation control for controlling grid-connected power electronics devices. The average switching frequency of the FSC-MPC is adjusted to be below the PI switching frequency for making a proper comparative study. It is evidenced that 
FSC-MPC strategy is capable of controlling the grid-tied inverters with superior performance compared to the PI control. It is found that FCS-MPC produces lower common-mode voltage, especially at lower operation points. Moreover, a significant reduction of the leakage current comes to more than $100 \%$ in some cases using FCS-MPC. On the other hand, PI control results in lower SSE and THD in all cases, however, FCS-MPC produces SSE and THD with acceptable limits.

\section{Acknowledgement}

The authors acknowledge the financial support received from the Scientific Research Deanship Project number 1-440-6178, Taif University, Saudi Arabia.

\section{References}

[1] Rehmani, Mubashir Husain, Martin Reisslein, Abderrezak Rachedi, Melike Erol-Kantarci, and Milena Radenkovic. "Integrating renewable energy resources into the smart grid: Recent developments in information and communication technologies." IEEE Transactions on Industrial Informatics 14, No. 7 (2018): 2814-2825

[2] Blaabjerg, Frede, Zhe Chen, and Soeren Baekhoej Kjaer. "Power electronics as efficient interface in dispersed power generation systems." IEEE transactions on power electronics 19, No. 5 (2004): 1184-1194

[3] Olivares, Daniel E., Ali Mehrizi-Sani, Amir H. Etemadi, Claudio A. Cañizares, Reza Iravani, Mehrdad Kazerani, Amir H. Hajimiragha et al. "Trends in microgrid control." IEEE Transactions on smart grid 5, No. 4 (2014): 1905-1919

[4] Tan KK, Zhao S, Xu JX. "Online automatic tuning of a proportional integral derivative controller based on an iterative learning control approach". IET Control Theory \& Applications. 2007 Jan 1;1(1):90-6

[5] Roman RC, Precup RE, Bojan-Dragos CA, Szedlak-Stinean AI. Combined model-free adaptive control with fuzzy component by virtual reference feedback tuning for tower crane systems. Procedia Computer Science. 2019 Jan 1;162:267-74

[6] Precup RE, Roman RC, Teban TA, Albu A, Petriu EM, Pozna C. "Modelfree control of finger dynamics in prosthetic hand myoelectric-based control systems". Studies in Informatics and Control. 2020 Dec $1 ; 29(4): 399-410$

[7] Preitl Z, Precup RE, Tar JK, Takács M. "Use of multi-parametric quadratic programming in fuzzy control systems". Acta Polytechnica Hungarica. 2006 Sep;3(3):29-43

[8] Haidegger T, Kovács L, Precup RE, Preitl S, Benyó B, Benyó Z. “Cascade control for telerobotic systems serving space medicine". IFAC Proceedings Volumes. 2011 Jan 1;44(1):3759-64 
[9] Turnip A, Panggabean J. "Hybrid controller design based magnetorheological damper lookup table for quarter car suspension". Int. J. Artif. Intell. 2020 Mar;18(1):193-206

[10] Twining, Erika, and Donald Grahame Holmes. "Grid current regulation of a three-phase voltage source inverter with an LCL input filter." IEEE transactions on power electronics 18, No. 3 (2003): 888-895

[11] Blaabjerg, Frede, Remus Teodorescu, Marco Liserre, and Adrian V. Timbus. "Overview of control and grid synchronization for distributed power generation systems." IEEE Transactions on industrial electronics 53, No. 5 (2006): 1398-1409

[12] Chung, Il-Yop, Wenxin Liu, David A. Cartes, Emmanuel G. Collins, and Seung-Il Moon. "Control methods of inverter-interfaced distributed generators in a microgrid system." IEEE Transactions on Industry Applications 46, No. 3 (2010): 1078-1088

[13] Rodriguez, Jose, and Patricio Cortes. Predictive control of power converters and electrical drives. Vol. 40. John Wiley \& Sons, 2012

[14] Vazquez, Sergio, Jose Rodriguez, Marco Rivera, Leopoldo G. Franquelo, and Margarita Norambuena. "Model predictive control for power converters and drives: Advances and trends." IEEE Transactions on Industrial Electronics 64, No. 2 (2016): 935-947

[15] Garayalde, Erik, Iosu Aizpuru, Unai Iraola, Iván Sanz, Carlos Bernal, and Estanis Oyarbide. "Finite control set mpc vs continuous control set mpc performance comparison for synchronous buck converter control in energy storage application." In 2019 International Conference on Clean Electrical Power (ICCEP), pp. 490-495, IEEE, 2019

[16] Guzman, Ramon, Luis Garcia de Vicuña, Antonio Camacho, Jaume Miret, and Juan M. Rey. "Receding-horizon model-predictive control for a threephase VSI with an LCL filter." IEEE Transactions on Industrial Electronics 66, No. 9 (2018): 6671-6680

[17] Vazquez, Sergio, Jose I. Leon, Leopoldo G. Franquelo, Jose Rodriguez, Hector A. Young, Abraham Marquez, and Pericle Zanchetta. "Model predictive control: A review of its applications in power electronics." IEEE industrial electronics magazine 8, No. 1 (2014): 16-31

[18] Rodriguez, Jos, Jorge Pontt, Csar A. Silva, Pablo Correa, Pablo Lezana, Patricio Cortés, and Ulrich Ammann. "Predictive current control of a voltage source inverter." IEEE transactions on industrial electronics 54, No. 1 (2007): 495-503

[19] Lai, Yen-Shin, Cheng-Kai Lin, and Fu-Pao Chuang. "Model-free predictive current control for three-phase AC/DC converters." IET Electric Power Applications 11, No. 5 (2017): 729-739 
[20] Hu, Jiefeng, Jianguo Zhu, and David G. Dorrell. "Model predictive control of inverters for both islanded and grid-connected operations in renewable power generations." IET Renewable Power Generation 8, No. 3 (2013): 240-248

[21] Rashwan, Ahmed, Mahmoud A. Sayed, Youssef A. Mobarak, Gaber Shabib, and Tomonobu Senjyu. "Predictive controller based on switching state grouping for a modular multilevel converter with reduced computational time." IEEE Transactions on Power Delivery 32, No. 5 (2016): 2189-2198

[22] Monteiro, Vítor, João C. Ferreira, Andrés Augusto Nogueiras Meléndez, and Joao Luiz Afonso. "Model predictive control applied to an improved five-level bidirectional converter." IEEE Transactions on Industrial Electronics 63, No. 9 (2016): 5879-5890

[23] Song, Zhanfeng, Changliang Xia, and Tao Liu. "Predictive current control of three-phase grid-connected converters with constant switching frequency for wind energy systems." IEEE Transactions on Industrial Electronics 60, No. 6 (2012): 2451-2464

[24] Young, Héctor, and Jose Rodriguez. "Comparison of finite-control-set model predictive control versus a SVM-based linear controller." In 2013 $15^{\text {th }}$ European Conference on Power Electronics and Applications (EPE), pp. 1-8, IEEE, 2013

[25] Young, Hector A., Marcelo A. Perez, and Jose Rodriguez. "Analysis of finite-control-set model predictive current control with model parameter mismatch in a three-phase inverter." IEEE Transactions on Industrial Electronics 63, No. 5 (2016): 3100-3107

[26] Mosa, Mostafa, Robert S. Balog, and Haitham Abu-Rub. "Highperformance predictive control of quasi-impedance source inverter." IEEE Transactions on Power Electronics 32, No. 4 (2016): 3251-3262

[27] Ayad, Ayman, Petros Karamanakos, and Ralph Kennel. "Direct model predictive current control strategy of quasi-Z-source inverters." IEEE Transactions on Power Electronics 32, No. 7 (2016): 5786-5801

[28] Chen, Qihong, Xiaoru Luo, Liyan Zhang, and Shuhai Quan. "Model predictive control for three-phase four-leg grid-tied inverters." IEEE Access 5 (2017): 2834-2841

[29] Luo, Yixiao, Chunhua Liu, and Feng Yu. "Predictive current control of a new three-phase voltage source inverter with phase shift compensation." IET Electric Power Applications 11, No. 5 (2017): 740-748

[30] Victor, Matthais, Frank Greizer, Sven Bremicker, and Uwe Hübler. "Method of converting a direct current voltage from a source of direct current voltage, more specifically from a photovoltaic source of direct 
current voltage, into a alternating current voltage." U.S. Patent 7,411,802, issued August 12, 2008

[31] Babqi, Abdulrahman J., Zhehan Yi, Di Shi, and Xiaoying Zhao. "Model Predictive Control of H5 Inverter for Transformerless PV Systems with Maximum Power Point Tracking and Leakage Current Reduction." In IECON 2018-44 ${ }^{\text {th }}$ Annual Conference of the IEEE Industrial Electronics Society, pp. 1860-1865, IEEE, 2018

[32] Cherati, S. M., N. A. Azli, S. M. Ayob, and A. Mortezaei. "Design of a current mode PI controller for a single-phase PWM inverter." In 2011 IEEE Applied Power Electronics Colloquium (IAPEC), pp. 180-184, IEEE, 2011

[33] Agarwal, Nikunj, Md Waseem Ahmad, and Sandeep Anand. "Condition monitoring of dc-link capacitor utilizing zero state of solar PV H5 inverter." In $201610^{\text {th }}$ International Conference on Compatibility, Power Electronics and Power Engineering (CPE-POWERENG), pp. 174-179, IEEE, 2016

[34] Schauder, Colin, and Harshad Mehta. "Vector analysis and control of advanced static VAR compensators." In IEE Proceedings $C$ (Generation, Transmission and Distribution), Vol. 140, No. 4, pp. 299-306, IET Digital Library, 1993

[35] Babqi, Abdulrahman J., and Amir H. Etemadi. "MPC-based microgrid control with supplementary fault current limitation and smooth transition mechanisms." IET Generation, Transmission \& Distribution 11, No. 9 (2017): 2164-2172

[36] Vazquez, S., J. I. Leon, L. G. Franquelo, J. M. Carrasco, E. Dominguez, P. Cortes, and J. Rodriguez. "Comparison Between FS-MPC Control Strategy for an UPS inverter application in $\alpha-\beta$ and abc frames." In 2010 IEEE International Symposium on Industrial Electronics, pp. 3133-3138, IEEE, 2010

[37] Kouro, Samir, Patricio Cortés, René Vargas, Ulrich Ammann, and José Rodríguez. "Model predictive control—A simple and powerful method to control power converters." IEEE Transactions on industrial electronics 56, No. 6 (2008): 1826-1838

[38] Cortes, Patricio, Jose Rodriguez, Cesar Silva, and Alexis Flores. "Delay compensation in model predictive current control of a three-phase inverter." IEEE Transactions on Industrial Electronics 59, No. 2 (2011): 1323-1325

[39] Cortés, Patricio, José Rodríguez, Daniel E. Quevedo, and Cesar Silva. "Predictive current control strategy with imposed load current spectrum." IEEE Transactions on power Electronics 23, No. 2 (2008): 612-618

[40] Barater, Davide, Giampaolo Buticchi, Emilio Lorenzani, and Carlo Concari. "Active common-mode filter for ground leakage current reduction 
in grid-connected PV converters operating with arbitrary power factor." IEEE Transactions on Industrial Electronics 61, No. 8 (2013): 3940-3950

[41] Duffey, Christopher K., and Ray P. Stratford. "Update of harmonic standard IEEE-519: IEEE recommended practices and requirements for harmonic control in electric power systems." IEEE Transactions on Industry Applications 25, No. 6 (1989): 1025-1034 